\title{
When Worlds Collide - Or Do They? Implications of Explanatory Coexistence for Conceptual Development and Change
}

\author{
Commentary on Evans \& Lane, Harris, Legare \& Visala, and Subbotsky
}

Susan A. Gelman

University of Michigan, Ann Arbor, Mich., USA

\author{
Key Words \\ Conceptual change $\cdot$ Conceptual coherence $\cdot$ Explanatory coexistence $\cdot$ \\ Human rationality
}

In season 7, episode 8 of the popular US television series Seinfeld, the character George Costanza is distressed to learn that his fiancée wants to socialize with his friends from his bachelor days. George has a theory that he inhabits two distinct 'worlds': the world of his friends ('independent George') and the world of his fiancée ('relationship George'). Each world operates smoothly on its own, but together they are dangerously incompatible. If the two worlds interact, the results will be disastrous. In George's words, 'Anybody knows, ya gotta keep your worlds apart.'

George's concern about worlds colliding provides a metaphor for thinking about the belief systems of science (on the one hand) and religion, magic, or supernatural entities (on the other hand). To what extent do these different ways of construing reality represent distinct realms that are best kept apart, like the two worlds of George Costanza? And what happens if they make contact? Can they peacefully coexist, or will one overwhelm and destroy the other? The fascinating and important papers in this volume by Harris [this issue], Legare and Visala [this issue], Subbotsky [this issue], and Evans and Lane [this issue] speak about these issues. In my comments, I will review some of their major contributions, and then focus on the implications for cognition more broadly.

\section{Contributions}

The papers in this volume richly illustrate Harris's [this issue] point that, contrary to Piaget, cognitive development is not strictly a process of 'progressive enlightenment' or increasing appeal to evidence-based evaluation of scientific data. Universal-

\section{KARGER}

Fax +41613061234

E-Mail karger@karger.ch

www.karger.com (c) 2011 S. Karger AG, Basel

Accessible online at: www.karger.com/hde
Susan Gelman

Department of Psychology

University of Michigan, 530 Church St

Ann Arbor, MI 48109-1043 (USA)

E-Mail gelman@umich.edu 
ly, the adult end point is one in which biologically plausible or scientifically informed beliefs sit alongside beliefs that can be characterized loosely as magic, superstition, religion, or supernatural reasoning [see also Hood, 2009]. Adults hold beliefs that are either unsupported by scientific evidence or directly in conflict with it. Most American adults believe that life continues after death [Harris, this issue], even after all biological processes cease. Adults in South Africa appeal to witchcraft to explain the onset of illness [Legare \& Visala, this issue], despite having a rich knowledge of infectious agents, contagion, and germs. British adults possess a lingering belief in magic that seeps into their judgments even when they try to mask it [Subbotsky, this issue], and in work that has deep implications for education, many US adults find creationist accounts more appealing than biological evolution [Evans \& Lane, this issue].

A striking observation in this work is that the developmental process argues against enlightenment as well: nonscientific beliefs do not uniformly lessen with age, and in some cases even increase into adulthood. For example, Harris and his colleagues found that an understanding of death proceeds from a consistently biological model in early childhood to a mixed model in adulthood in which religious concepts are added on. In Harris's [this issue] view, an understanding of biology may even be a 'conceptual prerequisite' for understanding nonbiological, supernatural forces. Thus, it is not the case that nonscientific beliefs merely reflect ignorance. They are not found only in the absence of scientific understanding. Instead, nonscientific beliefs persist and flourish despite individuals having learned a scientific foundation.

Finally, these papers illustrate that acceptance of supernatural beliefs cannot be partitioned off in some way as peculiar or nonrepresentative. These beliefs are not embraced only by uneducated adults, they are not embraced only by a certain subset of the population, they are not evoked only in special contexts, and they are not restricted to explaining anomalous events for which natural explanations fail. Natural and supernatural beliefs coexist not just within a population, but also within an individual, and not just within an individual across contexts but even for an individual within a particular context. So, for example, Harris [this issue] found that a given individual may treat death as both final (biologically) and nonfinal (spiritually). Likewise, Legare and Visala [this issue] found that when explaining illness, an individual might appeal to witchcraft as responsible for putting a person in the path of a pathogen, which works by biological means.

The clear conclusion, then, is that scholars interested in development and cognition must take supernatural beliefs seriously, and incorporate them into their cognitive models or theories. I turn next to the implications of these papers for broad issues in cognitive development. In particular, I suggest that the studies of supernatural belief systems have important implications for theories of conceptual coherence, conceptual change, and human rationality.

\section{Implications for Conceptual Coherence}

One of the hallmarks of a scientific theory is coherence: different concepts and causal laws interrelate to form a consistent and systematic whole. They are not simply independent pieces of information. Within a coherent theory, changes in one concept affect other concepts. Whether commonsense theories have this structure is a question of enduring interest. A number of scholars have argued for coherence in the belief 
systems of nonexpert reasoners, including even young children. For example, a vitalist understanding of biology is reflected in beliefs about both human bodily functioning and death [Inagaki \& Hatano, 2002; Slaughter \& Lyons, 2003]; beliefs about species origin, species change, and variation are interrelated [Samarapungavan \& Wiers, 1997; Shtulman \& Schulz, 2008], and beliefs that substances are composed of tiny, invisible particles have ramifications for judgments of weight conservation as well as contamination [Au, Sidle, \& Rollins, 1993]. Yet others have argued that belief systems lack coherence and instead are weakly organized [e.g., diSessa, 1993; Kuhn, 1989]. Thus, many questions remain about this aspect of children's knowledge.

The study of supernatural reasoning provides a new perspective on this debate [see also Nguyen \& Rosengren, 2004]. Given the seeming inconsistency between, for example, science and magic, endorsing both sorts of processes may be taken as prima facie evidence for lack of coherence. Yet the current papers reach different conclusions. On the one hand, Harris [this issue] and Subbotsky [this issue] argued for a pervasive lack of coherence. It seems incoherent, for example, to posit that existence stops with death, but also that an individual continues after death. Yet Evans and Lane [this issue] and Legare and Visala [this issue] demonstrated ways in which natural and supernatural beliefs can be integrated coherently, such as positing witchcraft to explain why a particular individual got exposed to HIV, but understanding the bodily consequences of HIV within a biological framework. Indeed, one strength of Legare and Visala's piece is that it sets forth several ways in which coherence can be achieved: with target-dependent, synthetic, or integrating forms of reasoning.

Now the challenge is upon researchers to investigate more directly the issue of conceptual coherence. Questions include the following. Does introducing new information about natural processes influence beliefs about magic, or are the two realms separate spheres that are immune to knowledge reorganization from one to the other? What are the consequences of challenging individuals regarding seeming inconsistencies in their folk beliefs? Is there a developmental progression in the accessibility and use of the three kinds of coexistence outlined by Legare and Visala [this issue]? For example, are beliefs initially more piecemeal and become more integrated with development? What are the contexts that promote integration or awareness of contradictions? These questions are fruitful directions for future research.

\section{Implications for Conceptual Change}

Conceptual change is an issue of tremendous importance, for both theory and application. From a theoretical standpoint, the question gets at the heart of what cognitive development is all about. A key theme in cognitive development has been that children possess intuitive theories of physics, biology, and psychology [see Gelman \& Legare, in press; Wellman \& Gelman, 1998], and that conceptual change is like theory change in science, with fundamental reorganizations of what constitute the very concepts in a domain [Carey, 2009]. As new beliefs are encountered, and inconsistencies are noted, concepts undergo striking change. Thus, for example, children's concept of 'living things' undergoes a reorganization as children learn that plants share important features with animals, such as the ability to engage in goal-directed activity [Opfer \& Siegler, 2004]. From a practical standpoint, conceptual change needs to be understood if we are to understand how to design educational interven- 
tions. For example, in order to teach people scientifically accurate laws of physics, it is typically assumed that we must understand, confront, and dismantle their preexisting misconceptions [McCloskey, 1983].

A potential implication of the work on supernatural reasoning is that conceptual change may turn out to be rather shallow. Old beliefs may hang on. For example, Evans and Lane [this issue] noted that it is often assumed that science instruction will supplant nonscientific beliefs such as creationism. Yet both Evans and Lane [this issue] and Legare and Visala [this issue] reminded us that natural or scientific explanations do not automatically replace supernatural or religious ones. Adults who have obtained a great deal of knowledge about biological illness processes do not abandon their beliefs about witchcraft; if anything, such nonscientific beliefs increase at the same time that biological knowledge increases [Legare \& Gelman, 2008]. Similarly, adults who have learned about evolution do not abandon essentialist views [Shtulman \& Schulz, 2008]. Thus, the present papers suggest that when new beliefs come in, they coexist with old beliefs, sitting side by side and not necessarily triggering conceptual change.

It would be valuable in future research to examine the depth of commitment to conceptual change more directly. For example, do supernatural beliefs show up on speeded tasks, akin to Kelemen and Rosset's [2009] work on teleological reasoning? At the very least, these results raise the question of what contexts encourage belief change and/or which sets of beliefs are viewed as incompatible. As Subbotsky asked: Why do some beliefs that contradict science persist and others disappear?

\section{Implications for Human Rationality}

Perhaps the most contested implication of the current papers concerns human rationality. Simply holding beliefs that differ from those of modern scientists does not in itself provide evidence for irrationality. Aristotle mistakenly considered the Earth to be the unmoving center of the universe, but we would not wish to characterize Aristotle as irrational. Similarly, scientists who believed in the existence of phlogiston were not irrational; they were merely wrong. Irrationality of beliefs requires something more. Beliefs are irrational under at least two conditions: (a) if they are logically inconsistent or incompatible (e.g., believing both $\mathrm{P}$ and not-P), or (b) if they are immune to evidence.

Harris [this issue] argued that biological and religious concepts of death are 'mutually inconsistent conclusions ... [that] are incompatible with one another' thus, he argued for irrationality on the first criterion. Yet the seemingly opposing frameworks of biology and religion can be reconciled within a dualist framework: bodily processes cease at death, but psychological or spiritual processes continue [Harris \& Giménez, 2005]. Such concepts are no more inconsistent than our ability to construe an entity as both physical and psychological (e.g., a book can be both musty and suspenseful; a person can be both strong and thoughtful) [Srinivasan \& Snedeker, 2011].

Subbotsky [this issue] suggested that people who consciously reject magical accounts nonetheless maintain a subconscious (presumably untestable) belief in magic - thus, he argued for irrationality on the second criterion. Although magic and religion may be incompatible with science, it is not clear that there is a principled distinction. Indeed, Evans and Lane [this issue] argued that 'natural and supernatu- 
ral explanatory systems are both derived from and anchored in universally available intuitive conceptual frameworks.'

In order to examine this question, one would need to probe more deeply to determine the mental processes associated with these different modes of reasoning. The ancient study of stars and the ancient study of gods were comparable - perhaps indistinguishable - processes (making observations and inferences on the basis of partial evidence); they differ only in our (modern) appraisal of the ontological status of stars versus gods. More generally, religious beliefs are not considered outside the realm of evidence or reasoned debate. Certainly one can get very analytical about religious beliefs (see, for example, discussions of the Torah in the Jewish tradition), and even make use of empirical evidence to bolster a theological point (e.g., those who look for evidence of Noah's ark, or who argue that fossils are tricks to test one's faith, or who scrutinize medical evidence to determine whether a person is qualified for sainthood).

Conversely, one can simply appeal to reputation when accepting scientific claims. Leaving aside the practice of science, conducted by scientists, much of what children and adults alike believe about the world is due to trust in expert testimony, whether these beliefs are scientific or religious [Gelman, 2009; Harris \& Koenig, 2006]. We do not go around insisting on first-hand evidence for all of our beliefs. Few people have personally verified the age of the earth, but most accept the expert testimony of geologists. A division of cognitive labor is a rational and efficient process [Lutz \& Keil, 2003], given constraints on human knowledge seeking and the human capacity to learn from others [Csibra \& Gergely, 2009; Tomasello, 1999]. From this perspective, religious and supernatural beliefs may be a by-product or extension of reliance on testimony for understanding natural processes, rather than a wholly distinct mind-set.

\section{Questions and Conclusions}

The papers in the current volume have common themes, but they also differ in important respects. I note just three here. First, the papers consider different kinds of 'supernatural' beliefs, including religion, witchcraft, and magic. One could add to this list superstitious practices (e.g., not walking under ladders), which may not even be accompanied by an articulable belief. Although there is a family resemblance to these perspectives, they also differ in important respects. For example, Subbotsky [this issue] argued that magic persists despite cultural pressures to the contrary. In contrast, religion is deeply supported by cultural institutions and explicit instruction. Woolley, Boerger, and Markman [2004] have demonstrated the importance of cultural support in maintaining supernatural beliefs, which is a topic that would be important to pursue in more depth.

A second point is that, although the papers agree that scientific and magical beliefs coexist, they disagree as to the nature of that relationship over development. Subbotsky [this issue] suggested that children and adults differ regarding whether magical beliefs are conscious (children) or subconscious (older children and adults). This seems inconsistent with both Harris [this issue] and Legare and Visala [this issue], where supernatural beliefs increased with age. Developmental evidence would shed light on the conditions that support supernatural reasoning at different points in development. 
Finally, a full consideration of these processes would require acknowledging emotional and moral concerns. We are not just talking about 'cold' cognition (evaluation of evidence), but also 'hot' cognition (motivated beliefs). Acceptance or rejection of supernatural beliefs relate to questions of identity (what makes us, as humans, unique?), fear of death, and social connectedness to others of a given religious or cultural group.

\section{Acknowledgement}

This research was supported by NICHD grant HD-36043 to Gelman.

\section{References}

Au, T.K., Sidle, A.L., \& Rollins, K.B. (1993). Developing an intuitive understanding of conservation and contamination: Invisible particles as a plausible mechanism. Developmental Psychology, 29, 286299.

Carey, S. (2009). The origin of concepts. New York: Oxford University Press.

Csibra, G., \& Gergely, G. (2009). Natural pedagogy. Trends in Cognitive Sciences, 13, 148-153.

diSessa, A.A. (2008). A bird's eye view of 'pieces' vs. 'coherence' controversy. In S. Vosniadou (Ed.), International handbook of conceptual change research (pp. 35-60). New York: Routledge.

Gelman, S.A. (2009). Learning from others: Children's construction of concepts. Annual Review of Psychology, 60, 115-140.

Gelman, S.A., \& Legare, C.H. (in press). Concepts and folk theories. Annual Review of Anthropology, 40.

Harris, P.L., \& Giménez, M. (2005). Children's acceptance of conflicting testimony: The case of death. Journal of Cognition and Culture, 5, 143-164.

Harris, P.L., \& Koenig, M.A. (2006). Trust in testimony: How children learn about science and religion. Child Development, 77, 505-524.

Hood, B. (2009). Supersense: Why we believe in the unbelievable. New York: HarperOne.

Inagaki, K., \& Hatano, G. (2002). Young children's naive thinking about the biological world. New York: Psychology Press.

Kelemen, D., \& Rosset, E. (2009). The human function compunction: Teleological explanation in adults. Cognition, 111, 138-143.

Kuhn, D. (1989). Children and adults as intuitive scientists. Psychological Review, 96, 674-689.

Legare, C.H., \& Gelman, S.A. (2008). Bewitchment, biology, or both: The co-existence of natural and supernatural explanatory frameworks across development. Cognitive Science, 32, 607-642.

Lutz, D.J., \& Keil, F.C. (2003). Early understandings of the division of cognitive labor. Child Development, 73, 1073-1084.

McCloskey, M. (1983). Intuitive physics. Scientific American, 248, 122-130.

Nguyen, S.P., \& Rosengren, K.S. (2004). Causal reasoning about illness: A comparison between European and Vietnamese-American children. Journal of Cognition and Culture, 4, 51-78.

Opfer, J.E., \& Siegler, R.S. (2004). Revisiting preschoolers' living things concept: A microgenetic analysis of conceptual change in basic biology. Cognitive Psychology, 49, 301-332.

- Samarapungavan, A., \& Wiers, R.W. (1997). Children's thoughts on the origin of species: A study of explanatory coherence. Cognitive Science, 21, 147-177.

Shtulman, A., \& Schulz, L. (2008). The relation between essentialist beliefs and evolutionary reasoning. Cognitive Science, 32, 1049-1062.

Slaughter, V., \& Lyons, M. (2003). Learning about life and death in early childhood. Cognitive Psychology, 46, 1-30.

Srinivasan, M., \& Snedeker, J.C. (2011). The role of generative structures in the representation and acquisition of polysemous words. Biennial meeting of the Society for Research in Child Development, Montreal.

Tomasello, M. (1999). The cultural origins of human cognition. Cambridge: Harvard University Press.

Wellman, H.M., \& Gelman, S.A. (1998). Knowledge acquisition in functional domains. In D. Kuhn \& R. Siegler (Eds.), Handbook of child psychology: Cognition, perception, and language. Vol. 2 (5th ed., pp. 523-573). New York: Wiley.

Woolley, J.D., Boerger, E.A., \& Markman, A.B. (2004). A visit from the Candy Witch: Factors influencing young children's belief in a novel fantastical being. Developmental Science, 7, 456-468. 